\title{
Finite element 3D numerical simulation study of car braking systems and brake disc/drum - pad/shoe friction couple materials
}

\author{
George Ipate ${ }^{1, *}{\text { Filip } \text { Ilie }^{2} \text { and Andreea Catalina Cristescu }}^{1}$ \\ ${ }^{1}$ University POLITEHNICA of Bucharest, Department of Biotechnical Systems, 313 Spl. Independentei, Romania \\ ${ }^{2}$ University POLITEHNICA of Bucharest, Department of Machine Elements and Tribology, 313 Spl. Independentei, Romania
}

\begin{abstract}
Our study uses the finite element method of modeling and analyzing the functioning of a braking system for a modern vehicle, in terms of stress ditributions, structural deformation, wear and thermal gradient of the brake disc and drum. The 3D geometric model of system brake is designed using Solidworks, and the coupled thermal and structural analysis is performed with the ANSYS Workbench R16 program. The brake was applied when the car was $85.7 \mathrm{~km} / \mathrm{h}\left(\omega=125 \mathrm{rad} \cdot \mathrm{s}^{-1}\right)$, the duration of braking until the car stopped was $t=5 \mathrm{~s}$. For the given example, the coefficient of average friction during braking, considering the pressure on the $\operatorname{pad} p=7.5 \mathrm{MPa}$, is $\mu=0.35$. It was discovered that the relative deformations of the plate and disc are larger in the area of the outer diameter than that of the inner diameter. This is also outlined by the fact that the pressure is higher on the outer sides than on the inner sides of the plate, the highest value being in the central axis zone of the outer side. Knowing the thermophysical characteristics of the disc and the plate and the working conditions, it was possible to determine the temperature variation during braking. The results of the numerical research revealed that an increase of the contact pressure and / or the relative speed between the contact surfaces implies an increase of the amplitude of the stick-slip phenomenon.
\end{abstract}

\section{Introduction}

The braking system is used to decrease the velocity of the car to a desired value or even to stop it, immobilizing the car in a stationary, on a horizontal road or on a slope, maintaining the constant speed of the car in the event of descending long slopes. The efficiency of the brakes is evaluated by the distance on which a car stops at a certain speed. The braking system consists of the brakes themselves and the brake actuation mechanism. Depending on the shape of the rotating part, the brakes themselves can be drum (radial), disc (axial) and combined. According to the form of the parts that produce the brakes, they are distinguished: brakes with shoes, brakes with tape and brakes with discs $[1,8,9]$.

The main role of a rubbing material is to generate a high coefficient of friction and, at the same time, it should have a very high wear resistance. Wear of the rubbing material is one of the important characteristics of the brake pads. A good functioning is closely associated with the quality of the material, as well as with the safety in operation, and of course it is directly related to the life of the brakes [2].

Söderberg and Andersson [3] investigated how wear of the pad-to-rotor interface can be predicted using general purpose finite element analysis software. They develop a three-dimensional finite element model of the brake pad and the rotor to compute the pressure maps in the pad-disc contact, and used a comprehensive form of Archard's wear law and explicit Euler integration to reproduce the wear of the brake pad.

Hwang and $\mathrm{Wu}$ [4] and Belhocine [5] in their research investigate the temperature and thermal stress in the ventilated disc-pad brake during single brake. The temperature field leads to variation of the contact pressure distribution by the effects of the thermal expansion. Due to their braking stability, controllability and ability to provide a wide-ranging brake torque, braking system whit ventilated disc with straight vanes and drum brake is most popular and straightforward to make.

Zengh and Zangh [6] present a numerical model based on ANSYS APDL used for the design of drum brake. They study the static deformation and equivalent stress of drum. Zagrodzki et. all [7] present a transient finite element simulation with frictional heat generation, for the two-dimensional thermoelastic contact problem of a stationary layer between two sliding layers. By using an Abaqus commercial finite element package, they concluded that if the slip velocity is high enough, there will be uneven heating and low frequency vibrations known as "hot judder".

\footnotetext{
* Corresponding author: puiu.ipate@gmail.com
} 
The main objective of this work is to comprehend a numerical model with 3D finite elements of a combined braking system (axial and radial) of the cars to analyze the method of friction and wear of the braking systems using the Ansys Workbench program. During this paper, a thermal analysis and a structural analysis coupled to a given braking system are performed and its stability and rigidity are investigated. Theoretical modeling of the method of using the brake pad as a viscoelastic material and of the brake disc or drum, also as determining the effect of temperature on this process were also important objectives.

\section{Material and methods}

\subsection{Geometric and finite element modeling}

A detailed three dimensional model of a Dacia Logan automobile solid system brake assembly has been studied in this research. The 3D geometric model of system brake is designed using Solidworks. The mechanical characteristics and dimension of the disc/drum brakes (Gray cast iron) and pad/shoe (lignin) materials selected in the analysis are presented in Table 1.

Table 1. Material characteristics and dimension of brake disc and $\mathrm{pad} / \mathrm{drum}$ and shoe.

\begin{tabular}{|c|c|c|c|c|}
\hline Dimension / Property & Disc & $\mathrm{Pad}$ & Drum & Shoe \\
\hline Diameter inner (mm) & 61 & 100 & 62 & 210 \\
\hline Diameter outer $(\mathrm{mm})$ & 258.0 & 140.2 & 272 & 235 \\
\hline Thickness (mm) & 22.0 & 18 & 44 & 25 \\
\hline Density $\left(\mathrm{kg} / \mathrm{m}^{3}\right)$ & 7200 & 2030 & 7200 & 2030 \\
\hline Mass (kg) & 4.71 & 0.192 & 8.25 & 0.412 \\
\hline Young Modulus [MPa] & 110000 & 3180 & 110000 & 3180 \\
\hline Poissom's ratio & 0.28 & 0.35 & 0.28 & 0.35 \\
\hline $\begin{array}{l}\text { Thermal expansion coefficient } \\
{\left[\mathrm{mm} /{ }^{\circ} \mathrm{C}\right]}\end{array}$ & $1.1 \cdot 10^{-5}$ & $3.1 \cdot 10^{-6}$ & $1.1 \cdot 10^{-5}$ & $3.1 \cdot 10^{-6}$ \\
\hline Thermal conductivity (W/K.m) & 37 & 0.275 & 37 & 0.275 \\
\hline
\end{tabular}

A 3D tetrahedral method will be used for finite element mesh generation. Overall, 85856 nodes and 44867 elements are used for the disc and pads, respectively, 63309 nodes and 33677 elements are used for the drum and shoes (Fig.1).

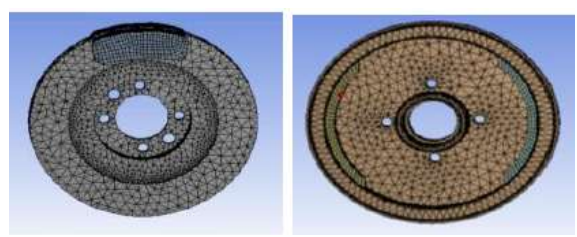

Fig. 1. Image capture of mesh of the ventilated disk (left) and drum brake (right) models.

Frictional wear can be expressed by applying a wear model between contact elements. To study tribological behaviour a frictional contact pair was established between disc-pad and drum-shoe interfaces. The used element types were Conta175 to represent contact and sliding between two surfaces and Target 170 for the associated contact elements.

\subsection{Boundary condition}

The investigation of the dynamic behaviour of physical systems is conducted with mathematical examples consisting of ordinary differential equations. In the present simulation, friction coefficient of contact pair is 0.35 and initial temperature is $22^{\circ} \mathrm{C}$. The gray cast iron is material of disc and drum. The geometrical dimensions and material characteristics of the brake disc, pad, drum and shoe are presented in Table 1. The wheel is decelerated at an starting velocity of $87.5 \mathrm{~km} / \mathrm{h}(125 \mathrm{rad} / \mathrm{s})$, to the final velocity $0 \mathrm{~km} / \mathrm{h}$ in $5 \mathrm{~seconds}$ and mechanical energy is transformed into the thermal energy. The brake pressure 7.5 MPa is imposed on the pad and shoe to generate the brake force. Figure 2 illustrates the boundary conditions applied to both geometry simulation model. 

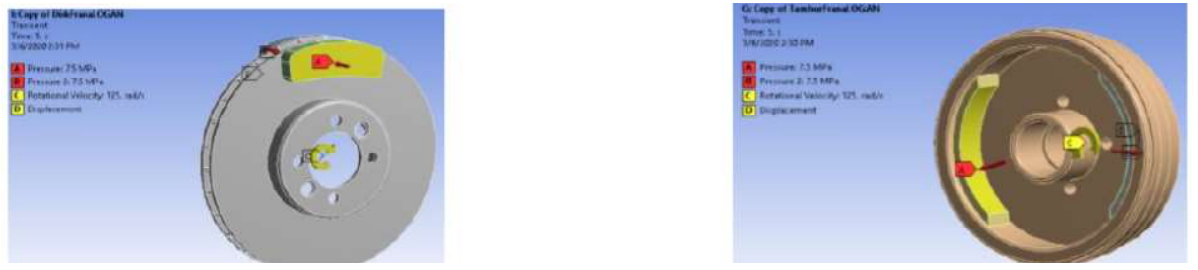

Fig. 2. Boundary condition in simulation program: disc-pad brake (left) and drum-shoe brake (right); (A) and (B) is the pressure = $7.5 \mathrm{MPa},(\mathrm{C})$ is rotational velocity $=125 \mathrm{rad} / \mathrm{s}$ and $(\mathrm{D})$ is displacement

The transient dynamic structural analysis performed with the Ansys program determines the structure's response to tasks that vary arbitrarily (randomly) over time. In a transient dynamic analysis equation of motion is:

$$
[M]\{\ddot{u}\}+[C]\{\dot{u}\}+[K]\{u\}=\{F(t)\}
$$

where, $[\mathrm{M}]$ is mass matrix, $[\mathrm{C}]$ is damping matrix, $[\mathrm{K}]$ is stiffness matrix, $\{\ddot{u}\}$ is nodal acceleration vector, $\{\dot{u}\}$ is nodal velocity vector, $\{\mathrm{u}\}$ is nodal displacement vector and $\{\mathrm{F}(\mathrm{t})\}$ is load vector. At any given time $\mathrm{t}$, these equation can be tought of a set of "static" equilibrium equations that also take into account inertia and damping forces. To solve this equation Ansys program uses the Newmark time integration algorithm, whith integration time step. Thermal solution is obtained by solving first order differential equation:

$$
\left[C^{t}\right]\{\dot{T}\}+\left[K^{t}\right]\{T\}=\{Q(t)\}
$$

where, $\left[\mathrm{C}^{\mathrm{t}}\right]$ is specific heat matrix, $\left[\mathrm{K}^{\mathrm{t}}\right]$ is thermal conductivity matrix, $\{\mathrm{T}\}$ is nodal temperature vector and $\{\mathrm{Q}(\mathrm{t})\}$ is sum of the element heat generation load and element convection surface heat flow vectors. If we apply to the equations of motion and conservation of the heat flux the variational principle, coupled with the thermoelastic constituent equations, will produce the following finite element matrix equation:

$$
\left[\begin{array}{cc}
{[M]} & {[0]} \\
{[0]} & {[0]}
\end{array}\right]\left\{\begin{array}{l}
\{\ddot{u}\} \\
\{\ddot{T}\}
\end{array}\right\}+\left[\begin{array}{cc}
{[C]} & {[0]} \\
{\left[C^{t u}\right]} & {\left[C^{t}\right]}
\end{array}\right]\left\{\begin{array}{l}
\{\dot{u}\} \\
\{\dot{T}\}
\end{array}\right\}+\left[\begin{array}{cc}
{[K]} & {\left[K^{u t}\right]} \\
{[0]} & {\left[K^{t}\right]}
\end{array}\right]\left\{\begin{array}{l}
\{u\} \\
\{T\}
\end{array}\right\}=\left\{\begin{array}{l}
F(t) \\
Q(t)
\end{array}\right\}
$$

where, $\left[\mathrm{C}^{\mathrm{tu}}\right]$ is thermoelastic damping matrix and $\left[\mathrm{K}^{\mathrm{ut}}\right]$ is thermoelastic stiffness matrix.

\subsection{Numerical model of wear}

Assuming the wear operation is a dynamic process and the estimation of the process as an initial value problem. In these situations a pattern of wear proposed by Archard is given by [3]:

$$
\frac{d w(t)}{d t}=f(\text { load, velocity, temperature, material })
$$

The Archard wear model calculate rate of volume loss $(\mathrm{dw} / \mathrm{dt})$ due to abrasion wear friction. Introducing the dimensional wear coefficient $\mathrm{k}$ (specific wear rate) an expression to calculate wear local, if the contact pressure and sliding velocity is known, is obtained:

$$
\frac{d w(t)}{d t}=k * p(t) * v_{s}(t)
$$

where, $\mathrm{k}=\mathrm{K} / \mathrm{H}, \mathrm{K}$ is wear coefficient addicted to the contact-pair $\left[\mathrm{mm}^{3} / \mathrm{m}\right], \mathrm{H}$ is material hardness $[\mathrm{MPa}]$, $\mathrm{p}(\mathrm{t})$ is the contact pressure $[\mathrm{MPa}]$ and $\mathrm{v}_{\mathrm{s}}(\mathrm{t})$ represents the relative sliding velocity $[\mathrm{mm} / \mathrm{s}]$. The wear is calculated by numerical integration of Eq. (5) corresponding to the explicit Euler integration scheme during the step $\Delta \mathrm{t}$, if the contact pressure in every node is known. The wear depth after the $t$ simulation step is then :

$$
w_{t+1}=w_{t}+\Delta t * f\left(t, w_{t}\right)
$$

The contact pressure in the wear process can be also obtained, corresponding to the law of motion, by the next equations:

$$
p(t)=b_{1} * t+b_{2}
$$

where $b_{1}=1.4143, b_{2}=4.811$ are parameters that depend on the particle size and material properties. The relative sliding velocity can be obtained, by the following first-order equations:

$$
v_{s}(t)=\mathrm{a}_{1} * t+a_{2}
$$

where $\mathrm{a}_{1}=0.0001$ and $\mathrm{a}_{2}=0.0021$ are parameters computed by regression of simulated data. 


\section{Results and discussions}

Due to their simplicity, the disc and plated brakes, respectively with the drum and the inner shoes are widespread in cars. At the action of the pads on the disc, respectively, of the sabotages on the drum, between them appear frictional forces that can give rise to a moment of braking, which is opposed to the movement of the car. Under the action of the braking moment, in the contact area of the wheel with the road, the reaction directed in the opposite direction of the movement is born. During braking, due to the friction that occurs between the drum and the friction pads of the shoes, the kinetic energy of the car turns into heat $[5,10,11]$.

To investigate the maximum temperature, rise after the braking operation a transient thermal analysis is performed on the ventilated disc and drum brake. Boundary conditions applied for the transient thermal analysis are an heat flux transfer of $1.5395 \mathrm{~W} / \mathrm{mm}^{2}$ applied over the swept zone of both the pads and shoe while the direction of heat flow is towards the disc and an thermal convection applied on all the surfaces with the air coefficient of $5 \mathrm{e}-6 \mathrm{~W} / \mathrm{mm}^{2} \mathrm{~K}$. The analysis starting at initial temperature of $22^{\circ} \mathrm{C}$.

Fig. 3 describe the temperature maps on the friction contacts on the transient (at $\mathrm{t}=0.55 \mathrm{~s}, \mathrm{t}=2.22 \mathrm{~s}, \mathrm{t}=3.88 \mathrm{~s}, \mathrm{t}=5 \mathrm{~s}$ ) results. As expected, the tendency is for the temperature results to converge to the steady state. It can be easily observed for the disc-plate assembly, a maximum temperature of $463{ }^{\circ} \mathrm{C}$ is obtained for the initial conditions set as design variables. The temperature and total heat flux conturs for the drum -shoes assembly is shown in Fig.4. Similarly, the maximum temperature of $279.2{ }^{\circ} \mathrm{C}$ is reached for the drum on the friction surface with the brake shoe.

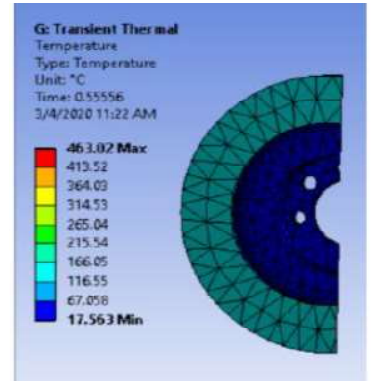

a) Time $\mathrm{t}=0.55 \mathrm{~s}$

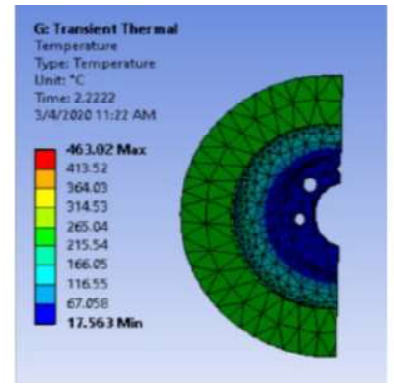

b) Time $\mathrm{t}=2.22 \mathrm{~s}$

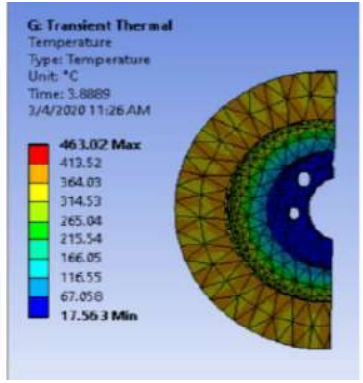

c) Time $\mathrm{t}=3.88 \mathrm{~s}$

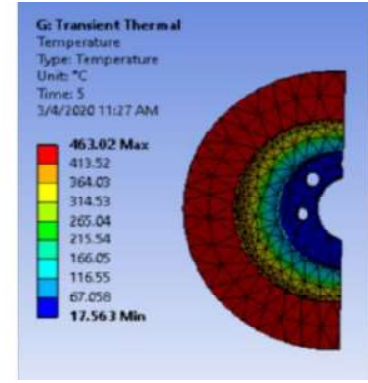

d) Time $\mathrm{t}=5 \mathrm{~s}$

Fig. 3. Temperature contours of gray cast iron disk
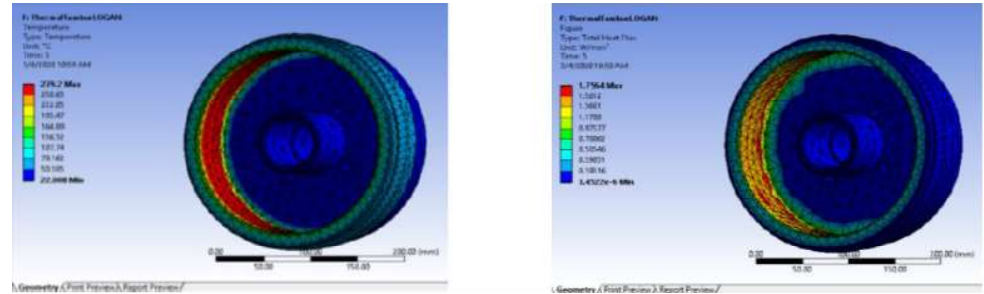

Fig. 4. Temperature (left) and total heat flux (right) contours of gray cast iron drum

Deformation analysis of the disk and drum. In accordance with the Fig. 5, it can be observed that the total displacement of pad brake is $0.3123 \mathrm{~mm}$. It indicates the fact that the deformation of the pad is relatively the same in comparing whit disk, $0.417 \mathrm{~mm}$. By the Fig. 6, it can be observed that the maximum total deformation of the drum is $0.2458 \mathrm{~mm}$, which means that the repartition along $\mathrm{X}$ axis is small (in the opposite direction to gravitational acceleration). Consequently, the next drum optimization should take into account the deformation of the drum edge.
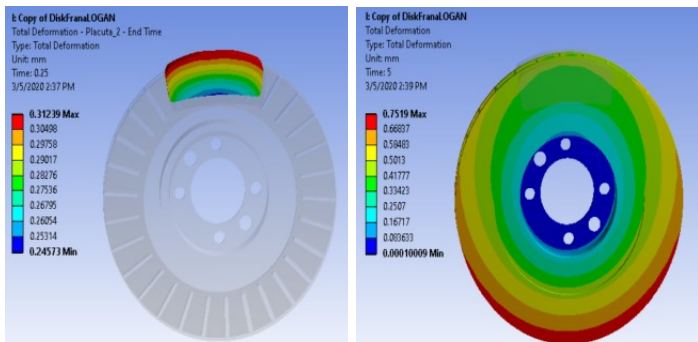

Fig. 5. Total displacement distribution on disc-pad.

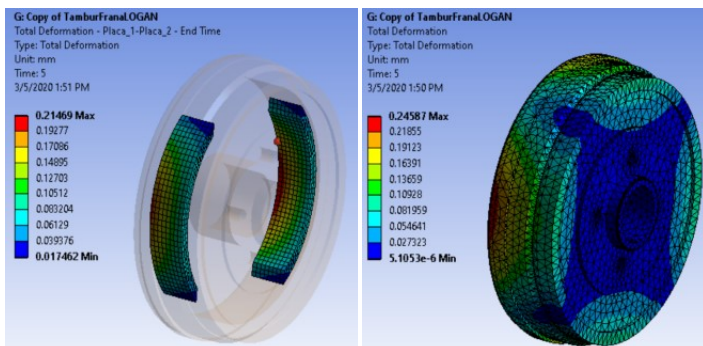

Fig. 6. Total displacement distribution on drum-shoe.

Stress analysis of the disk and drum. Fig.7-8. presents the maps of the equivalent Von Mises stress at the end of simulation, the range of results varying from 1.335 to $344.65 \mathrm{MPa}$ in case of disc-pad assembly, respectively from 0 to 77.6 $\mathrm{MPa}$ in case of drum-shoes assembly. The maximum value, $344.46 \mathrm{MPa}$ recorded during the simulations at the 
plate-disc torque is significantly different compared to the one obtained for the drum-shoe couple in the mechanical investigation performed under the identical conditions. It is observed the appearance of this value at the level of the disk bowl, because the disk is anchored to the wheel hub by means of screws, thus put a stop to its movement.
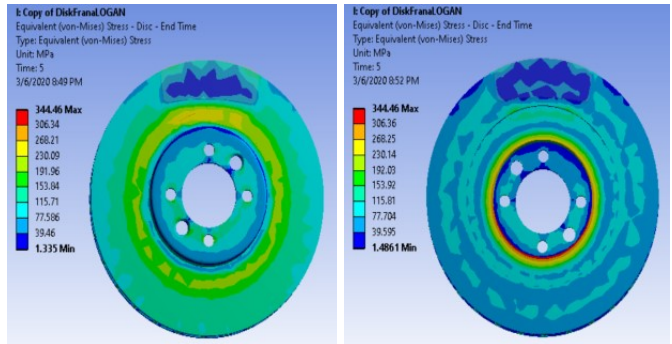

Fig. 7. Equivalent (von-Mises) stress repartition on inner disc (right) and outer disc (left)
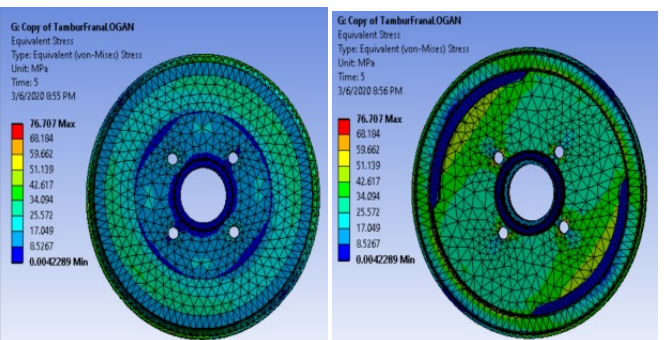

Fig. 8. Equivalent (von-Mises) stress repartition on inner drum (right) and outer drum (left)

Analyzing the stresses resulting from the simulation of the braking operation, at the contact among the shoe and the drum, the maximum tension is $77.6 \mathrm{MPa}$ and appears instead of the drum clamping in the lower part of the drum. The stress contour is evenly distributed on the surface of the drum, because the drum has a symmetrical structure.

In braking systems, the speed of sliding between the disk and the plates or between the drum and the shoe is variable (Fig. 9). In the field of low and very low speeds, due to the elasticity of the elements of the braking system, the phenomenon of stick-slip appears. The amplitude of this phenomenon is influenced by the rigidity characteristics of the system, the working speed and the frictional behavior of the couple of brake disc-plate materials.
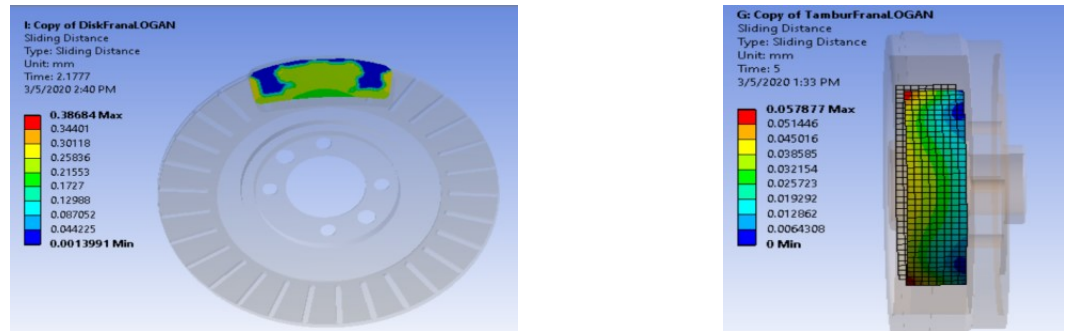

Fig. 9. Sliding distance contur results for disc-pad (left) and drum-shoe (right).

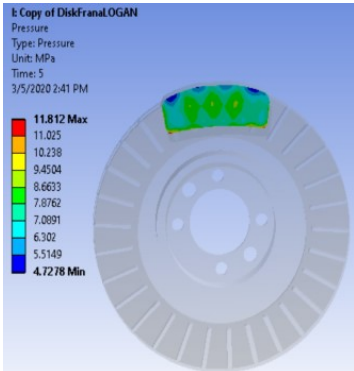

Fig. 10. Contact pressure distribution

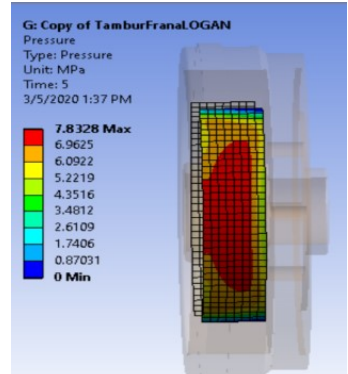

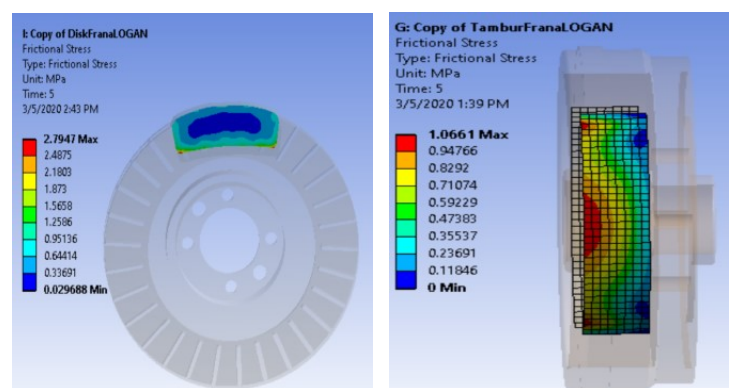

Fig. 11. Frictional stress distribution

Fig. 10 depict the contact pressure allocation in the friction interface of the inner pad taken at different times of virtual experiment. For this distribution, the range varies from 0 to $11.812 \mathrm{MPa}$ and grown to a maximum value at the moment $t=5 \mathrm{~s}$, which matched to the car stop. The distribution of the contact pressure at the surface of the disc, shows an uneven load field at the surface contact with the brake pad. Superior pressure values are discovered in the central area of contact of the plate with the disc, that can lead to regional wear and plastic deformation results. Lower pressure results are discovered along the outer edge of the plate contact with the disc. Fig. 11 shows the frictional stress distribution for both geometrical models. Given that the model takes into account the slip phenomenon, the resulting frictional stress variation is spurious. 

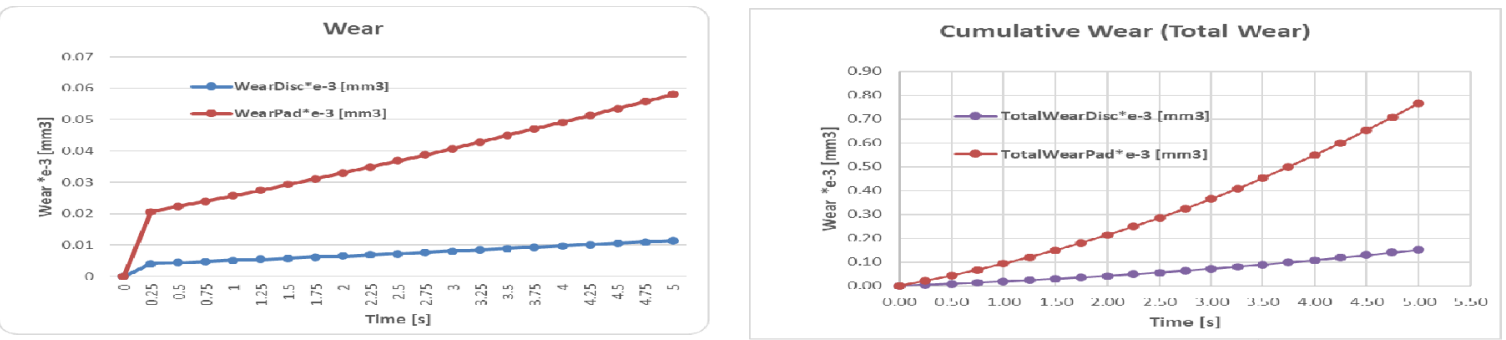

Fig. 12. The evolution in time of volumetric wear (left) and total volumetric wear (rigth) obtained during brake for disk (red line) and pad (blue line).

The simulation routine proposed is agreed to simulate the wear at the friction couple materials interface and implemented in VBExcel. Results from the virtual experiments, in the form of volumetric wear evolutions in time and the profile of cumulative wear (total volumetric wear), are shown in Fig. 12. The input data for solving the differential equation (Eq.5) starting from the initial condition $\mathrm{w}_{\mathrm{t}}(0)=0$, were: $\mathrm{K} \_$disc $=1066\left[\mathrm{~mm}^{3} / \mathrm{m}\right]$, H_disc $=720[\mathrm{MPa}]$, $\mathrm{K}$ pad $=906\left[\mathrm{~mm}^{3} / \mathrm{m}\right], \mathrm{H}$ pad $=120.7[\mathrm{MPa}]$, and an integration step $\Delta \mathrm{t}=0.25 \mathrm{~s}$. Evidently, mathematical model propose is a simplification of a process that was discussed to be a function of many factors. Clearly, Eq. (5) can be made more complex by adding effects of other phenomena such as presence of oxidation, for instance.

\section{Conclusions}

To study structural characteristic and the tribological behavior of the braking system of a car for this study, a simulation program was created in the Ansys Workbench environment. In drum braking systems, due to the frictional forces between the front shoe and the drum, the driving force of the rear shoe is higher compared to the driving force of the previous shoe. In this way, the braking moment increases substantially. In order to equalize the uses for the two shoes, constructive solutions are used, such as: smaller pressing forces or larger friction pads on the primary shoe compared to the secondary shoe. The results obtained by the method of finite element analysis provide reference values for optimum choice of materials used in the fabrication of a braking system, making the design of the disc or drum structure more efficient. At the same time, significant improvement of work efficiency and reduction of design time by using software such as ANSYS Workbench are observed. Also, it can be noted that the wear of the brake pad is about five times greater than that of the brake disc.

\section{References}

1. G. R. K. R. Ramachandru,V. Kumars, Open j. technol. eng. discip. , Dynamic analysis of mechanical braking system, 2, No. 4, 178-185, (2016).

2. R. B. Mathur, P. Thiyagarajan, T. L. Dhami, Carbon Science, Controlling the Hardness and Tribological Behaviour of Non-asbestos Brake Lining Materials for Automobiles, 5, No. 1, 6-11, (2004).

3. A. Söderberg, S. Andersson, Wear, Simulation of wear and contact pressure distribution at the pad-to-rotor interface in a disc brake using general purpose finite element analysis software, Vol. 267, 2243-2251, (2009).

4. P. Hwang, X. Wu, J Mech Sci Technol, Investigation of temperature and thermal stress in ventilated disc brake based on 3D thermo-mechanical coupling model, 24, 81-84, (2010).

5. A. Belhocine, M. Bouchetara, U.P.B. Sci. Bull., Thermomechanical analysis of vehicle Braking, Series D, Vol. 76, Iss. 1, (2014).

6. B. Zheng, J.D. Zhang, IOP Conf. Series: Materials Science and Engineering, Finite Element Analysis of the Brake Drum Based on ANSYS APDL, 472 012081, 1-7, (2019).

7. P. Zagrodzki, Raytech, K. B. Lam, E. Al Bahkali, J. R. Barber, J Tribol-T ASME, Nonlinear Transient Behavior of a Sliding System With Frictionally Excited Thermoelastic Instability, 123, 699 - 708, (2001).

8. G. Babukanth, M. Vimal Teja, IJMIE, Transient Analysis of Disk Brake By using Ansys Software, 2, Issue-1, 21-25, (2000).

9. A. Durgude, A. Vipradas, S. Kishore, S. Nimse, MAE 598-2016-11, Design optimization of brake disc geometry, Final Report, (2016).

10. N. A. Stoica, UPB, Contributions to the study of the tribological processes in the disc braking system, applied to automobiles, Doctoral thesis, București, (2018)

11. J.G.P. da Silva, C.H.S. Pereira, A. Casaril, P.E.D. Varante, H.A. Al-qureshi, SAE International, Modeling of the Elastic Modulus of Brake Pad Materials with High Viscoelastic Content, (2012). 